\title{
Preperformance Testing of a Website
}

\author{
Sushma Suryadevara and Shahid Ali \\ Department of Information Technology, AGI Institute, Auckland, New Zealand
}

\begin{abstract}
This study was conducted on the importance of performance testing of web applications and analyzing the bottleneck applications. This paper highlights performance testing based on load tests. Everyone wants the application to be very fast, at the same time, reliability of the application also plays an important role, such that user's satisfaction is the push for performance testing of a given application. Performance testing determines a few aspects of system performance under the pre-defined workload. In this study JMeter performance testing tool was used to implement and execute the test cases. The first load test was calculated with 200 users which was increased to 500 users and their throughput, median, average response time and deviation were calculated.
\end{abstract}

\section{KEYWORDS}

Performance testing, load balancing, threads, throughput, JMeter, load test

\section{INTRODUCTION}

Flipmind company started in 2005 by Michael Jones Owner and Director of the company with a dream helping clients. Flipmind creates software to help the business succeed in E-commerce Consulting \& Development, Website Design, Mobile Development, and Performance Analysis \& Optimization, etc. The company had delivered a lot of projects in New Zealand such as Forza, Park \& Fly, Money Place, My Ride, etc. The company has worked with Torpedo7 since 2006 providing BA, systems architecture, web \& e-commerce development \& load testing services, etc. Flipmind built the eCommerce platform powering Torpedo7 from the ground up. In New Zealand and Australia, Torpedo7 sells thousands of products and you would be hard- pressed to find a cyclist that does not buy from them. Flipmind company started in 2005 by Michael Jones Owner and Director of the company with a dream helping clients. Flipmind creates software to help the business succeed in E-commerce Consulting \& Development, Website Design, Mobile Development, and Performance Analysis \& Optimization, etc. The company had delivered a lot of projects in New Zealand such as Forza, Park \& Fly, Money Place, My Ride, etc. The company has worked with Torpedo7 since 2006 providing BA, systems architecture, web \& e-commerce development \& load testing services, etc. Flipmind built the eCommerce platform powering Torpedo7 from the ground up. In New Zealand and Australia, Torpedo7 sells thousands of products and you would be hard-pressed to find a cyclist that does not buy from them. Flipmind is one of the most rapidly growing company in New Zealand as it offers high-class service such as website development, testing and its maintenance updating the data regularly to its stakeholders. Currently working on a project named as Torpedo7 website. Torpedo7 is the most popular outdoor store in New Zealand. We can browse our huge selection of snow and water gear, bikes comfortable outdoor clothing for women, men, and kids, camping equipment, hiking gear, bags \& packs of all sizes, trampolines, and outdoor technology use in your next adventure. Nowadays, for every web application, everyone wants everything to be fast and at the same time, there is concern about the reliability of usage. Most of the users want to load their webpage 
rapidly fast so that they can finish and move to another work. If a page took a long time to load, the users will end up the task. The economic growth of any organization depends on the web application. If the application is not running fast, people lost interest in that application. So, it is important to do the performance testing of a web application for any organization. The load testing is done to test the performance of a website. By doing this performance testing we can know the system behaviour while handling specific load given by the customer to the system [4].

The main challenge for this project was to conduct the is load test to torpedo7.co.nz website for Black Friday and Christmas to make sure the website does not crash on those days. Load testing before Black Friday and Christmas or on any big event is very important for companies. The performance testing helps to fix bottlenecks, errors, and bugs due to high traffic spikes on the website. The cost of failure is the direct loss of sales and money to retailers. Using load testing failure can be easily avoided.

The scope of my project is to do a load test of the Torpedo7 website using JMeter for the Homepage, Shop feature(Snow, Technology, Clothing, Water, Bike), Service feature (Bike workshop), Search functionality, adding the item to the cart and proceed to checkout with 200, 500 users hence compared and analysed the results using summary report, graphs, CSV file and HTML report. The core of this objective is to make sure that the current application is optimal for handling increased traffic on the website. Hence to analyze and measure the performance of the Torepdo7 website we will be using the JMeter tool.

This research is organized as follow: Section 2 focuses on the literature review of various studies concentrating on automation regression. Section 3 is focused on the research methodology for this research. Section 4 of this research is focused on research execution results. Discussion to results of this research are provided in section 5. In section 6 conclusion to the research is provided. Finally, section 7 is dedicated towards the future work recommendations.

\section{LITERATURE REVIEW}

Many studies have been conducted in the past in favour of performance and load testing, we will investigate those studies, respectively.

A research was conducted on the Importance of performance testing of web applications and analysing the bottleneck applications [4]. This study highlights the performance testing based on the load test. Everyone wants the application to be very fast, at the same time, reliability of the application also plays an important role, such that user's satisfaction is the push for performance testing of a given application. Performance testing determines a few aspects of system performance under the pre-defined workload. Performance testing is measured when the business gets peak by its hits. Another research was conducted on different tools to do performance testing [7]. Apache JMeter is a free java application performance testing tool. It has a lot of plugins to aid the testing tools. Performance testing using JMeter is a type of testing to determine the responsiveness, throughput, interoperability, reliability, and scalability of an

application under a given workload. In today's competitive world it has become critical to the organizations to test their web application [8]. Load testing is the process of subjecting a whole system to a work level approaching its limits. Load testing is done to determine the behaviour of the system under normal conditions and peak load conditions. The objective of load testing is to determine the maximum capacity of an application. Another research was done on web services used mostly in all aspects of social life [9]. For web applications, performance testing is gaining wide attention. This study highlights first we analyse and research the types, and methods of performance testing of the web and later we do some testing process methods. 
A study was conducted that the performance tool was used to test web applications. This tool is used for performance, load and stress testing of web applications or websites [10].

Another research was conducted on web application performance testing which plays an important role in providing Quality of service [11]. This study highlights the performance testing of web applications using a reactive based framework which helps in reducing the cost and increases the efficiency of performance testing.

A performance testing framework for a rest-based web application was proposed [12]. This framework aims to provide software testers with an integrated process from test case design, test scripts, and test execution. Another research was conducted on ajax based web applications [13] which have gained more popularity since it brings the richness of desktop applications.

A research was conducted regarding challenges and experiences to identify a good solution for conducting performance testing on web applications [14]. There was another study conducted which described three open-source tools and compared their performance, usability and software requirements [12].

Testing web applications is nothing but finding errors [12]. This study highlights different performance testing tools and tried with JMeter to improve the performance of website or web application. There was another research conducted which provides the comparison of load testing tools (Sharma,2016). In this study the main load test tools available in the market and their advantages were discussed.

A study was conducted on performance testing concepts and comparative analysis of web applications [18]. The main objective of performance testing is not to identify bugs but to eliminate performance bottlenecks.

Performance testing and load testing are some of the means to evaluate web application performance [19]. This study highlighted the load test of web applications with JMeter using blaze meter in cloud-based load testing. Another study was conducted in comparison to tools [20]. In this research comparison of three different tools was compared with respect to response times.

All these studies highlight different aspects of performance testing. However, I believe that performance testing is very important for the success of the project. Hence in this project will perform performance testing on the torpedo7 website.

\section{RESEARCH METHODOLOGY}

Research methodology for performance testing of Torpedo website project has been discussed below.

\subsection{Comparative Analysis of Performance Tools}

Table 1 below shows the comparative analysis of performance tools. After doing comparative analysis selected JMeter as the best tool for my project. We have also selected JMeter since its open-source tool to use and have hands-on experience on JMeter. 


\begin{tabular}{|l|l|l|l|}
\hline CRITERIA & JMeter & LoadRunner & NeoLoad \\
\hline Commercial License & Open Source Tool & Yes & Yes \\
\hline Cost & Free & Expensive & Moderate \\
\hline Launched By & Apache Foundations & HP & Neoload \\
\hline Result Reporting & $\begin{array}{l}\text { Minimum Support (Need } \\
\text { additional plugins for } \\
\text { graphs) }\end{array}$ & Maximum Support & Maximum Support \\
\hline Browser Support & Support all browsers & Support all browsers & Support all browsers \\
\hline Load Generation & $\begin{array}{l}\text { Unlimited load } \\
\text { GENERATION }\end{array}$ & $\begin{array}{l}\text { Depending on the type of } \\
\text { license }\end{array}$ & $\begin{array}{l}\text { Depending on the type of } \\
\text { license }\end{array}$ \\
\hline Devise OS Support & $\begin{array}{l}\text { Supports Android, Linux, } \\
\text { Windows, Mac }\end{array}$ & Does not support Mac & Does not support Mac \\
\hline
\end{tabular}

Table 1:Comparitive analysis of performance tools

\subsection{Selected Tools for Project}

\subsubsection{Apache JMeter}

Apache JMeter is a most popular and open-source tool for testing the web applications which is best suited for the companies as they do not have to pay for it. It is $100 \%$ pure java application which is designed to load test functional behavior and measure performance of the application. It is specially designed for testing Web applications. Apache JMeter is used to test both on static and dynamic resources performance. It can be used to simulate a heavy load on the server to analyze overall performance under different load types. We can use to make a graphical analysis of performance test scripts under heavy load [3].

\subsubsection{Blazemeter}

Blazemeter is a Chrome extension that enables you to record, browse, upload and run. Using Blazemeter we can create proper test scripts and load scenarios. Blazemeter enables us to write test scripts using JMeter and user experience test scripts using Selenium. All we need is to write the test-scripts in Blazemeter, choose the number of load-engines and run the test. The system takes care of everything else. An unlimited number of load-engines are preconfigured and available at our disposal. Detailed graphical reports are generated during the load [2].

\subsection{Selected Methodology for Project}

A project run by Flipmind company works on the agile methodology for the development of web applications. In the company, the project is divided into sprints and each sprint runs for 1 week. Daily stand-up meetings and discussions will be held in the company to give a brief description of project progress and about the issues facing [5]. 


\subsubsection{Workflow of JMeter}

Figure 1 shows the workflow of JMeter. When we start to perform the test of an application, JMeter creates requests to target servers and simulates the number of users by sending requests to the target server. Once the server starts responding to the requests JMeter saves all the responses. By using the response JMeter collects data to calculate statistical information. Finally, based on this information JMeter prepares a report about the performance of the Application under test.

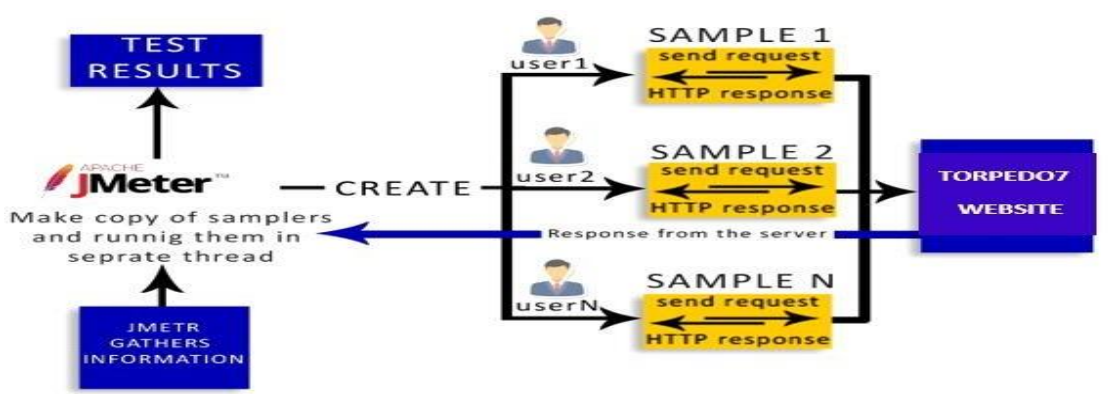

Figure 1: JMeter Workflow for Project

\section{Project Execution}

\subsection{Test Plan}

Table 2 below shows the test plan for my project. Table 2 is more focused on the test plan for the project of the Torpedo7 website and how I generated reports with different users.

\begin{tabular}{|c|c|}
\hline Document & Performance Test Plan \\
\hline Project & Torpedo7 website \\
\hline Version & 1.0 .0 \\
\hline \multicolumn{2}{|c|}{$\begin{array}{l}\text { The objective of this document is to outline the environment and Performance test Plan for the } \\
\text { Torpedo7 website and to ensure if the current system architecture is optimal for handling increased } \\
\text { traffic on the website and also, to figure out if there are any upgrades that need to be done. }\end{array}$} \\
\hline \multicolumn{2}{|l|}{ Scope } \\
\hline \multicolumn{2}{|c|}{$\begin{array}{l}\text { - Load test the Homepage, Shop feature (Snow, Technology, Clothing, Water, Bike), Service } \\
\text { feature (Bike workshop), Search functionality, adding the item to the cart and proceed to } \\
\text { checkout functions of Torpedo7 website for } 200 \text { users and } 500 \text { users }\end{array}$} \\
\hline \multicolumn{2}{|c|}{ - Analyze test results. } \\
\hline \multicolumn{2}{|c|}{ - Identify bottlenecks. } \\
\hline \multicolumn{2}{|c|}{ - Propose suggestions. } \\
\hline \multicolumn{2}{|c|}{ Out of Scope } \\
\hline \multicolumn{2}{|c|}{ - Functional or accuracy testing of the Torpedo7 website. } \\
\hline \multicolumn{2}{|c|}{ - Browser or software compatibility testing. } \\
\hline - $\mathrm{A}$ & testing types not included in the Scope section. \\
\hline
\end{tabular}




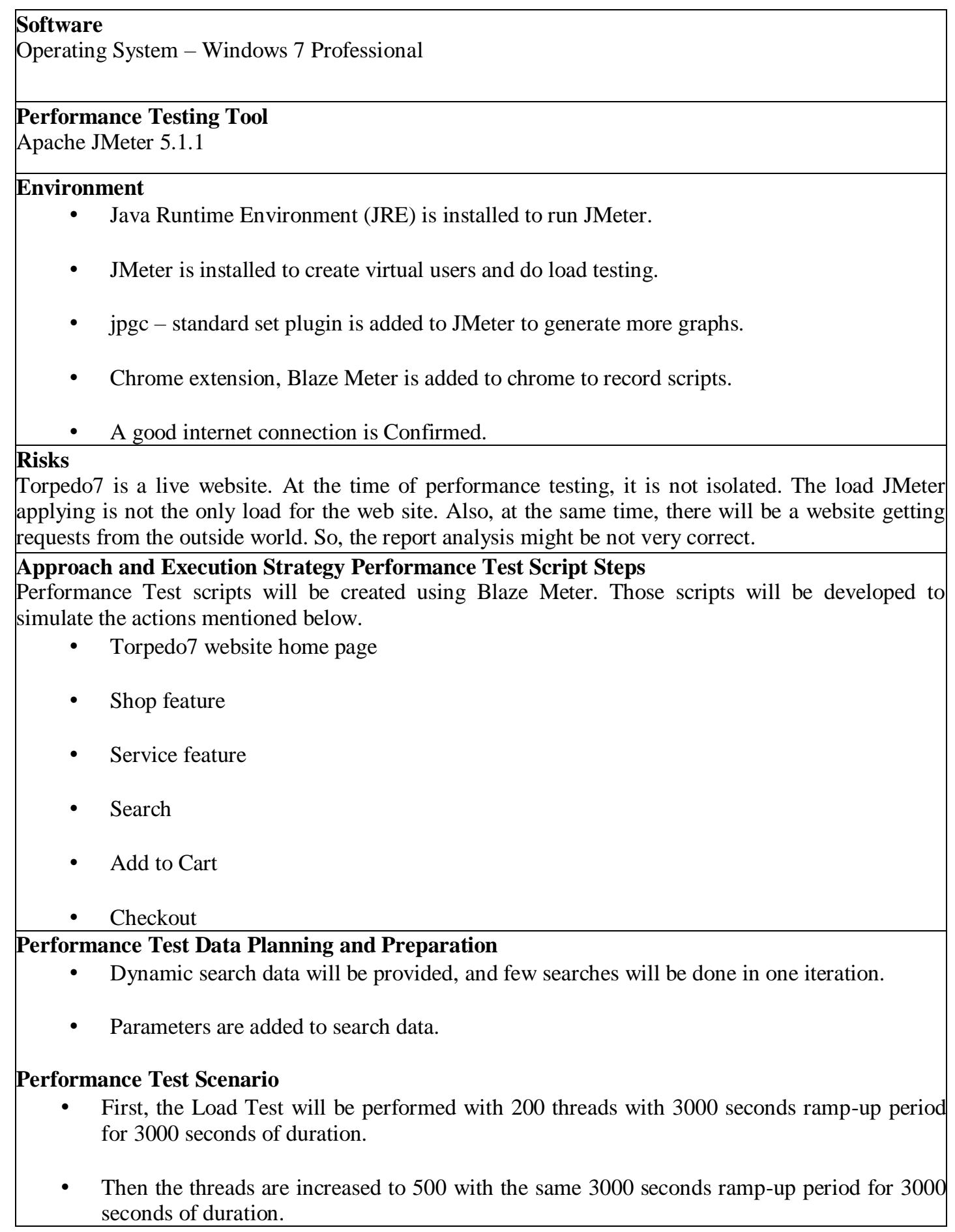




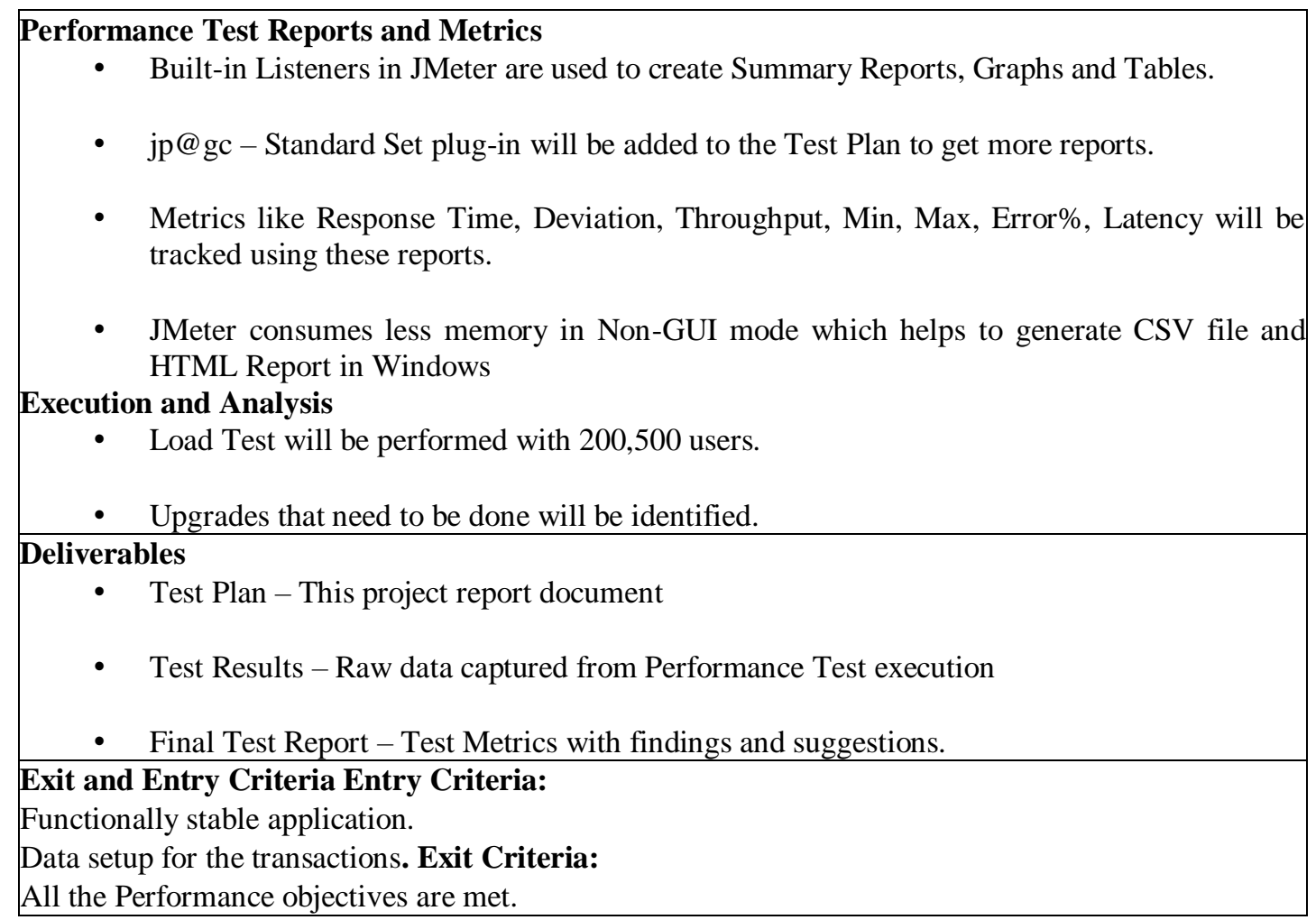

Table 2:Test plan for the Project

\subsection{Performance Test Cases}

The performance test cases for this project are shown in table 3 . Table 3 test cases $2,13,14,19$ and 20 are the main features of this torpedo7 website.

\begin{tabular}{|l|l|l|l|}
\hline $\begin{array}{l}\text { Test Case } \\
\text { ID }\end{array}$ & Step Description & Expected Output & $\begin{array}{l}\text { Transaction } \\
\text { Name }\end{array}$ \\
\hline TC_001 & $\begin{array}{l}\text { 1. Open the Chrome browser2. Enter } \\
\text { the URL 3. Enter the valid Email and } \\
\text { Password4. Click the } \\
\text { sign-in button }\end{array}$ & $\begin{array}{l}\text { User should be landed on the } \\
\text { Torpedo7 Login Page and should } \\
\text { be logged in } \\
\text { successfully }\end{array}$ & User login \\
\hline TC_002 & $\begin{array}{l}\text { User click on Shop icon and navigate } \\
\text { to snow page }\end{array}$ & Snow page is displayed & Snow page \\
\hline TC_003 & $\begin{array}{l}\text { User click on Snowboarding and } \\
\text { navigate to snowboarding page }\end{array}$ & Snowboarding page is displayed & $\begin{array}{l}\text { Snow Boarding } \\
\text { page }\end{array}$ \\
\hline TC_004 & $\begin{array}{l}\text { User click on Shop icon and navigate } \\
\text { to technology page }\end{array}$ & Technology page is displayed & Technology page \\
\hline TC_005 & $\begin{array}{l}\text { User click on phone and navigate to } \\
\text { the phone page }\end{array}$ & Phone page is displayed & Phone page \\
\hline TC_006 & $\begin{array}{l}\text { User click on Shop and navigate to } \\
\text { clothing and footwear }\end{array}$ & Clothing page is displayed & Clothing page \\
\hline TC_007 & $\begin{array}{l}\text { User click on women's and navigate } \\
\text { to women's page }\end{array}$ & Women page is displayed & Women page \\
\hline TC_008 & $\begin{array}{l}\text { User click on Shop icon and navigate } \\
\text { to the water }\end{array}$ & Water page is displayed & Water page \\
\hline
\end{tabular}




\begin{tabular}{|c|c|c|c|}
\hline TC_009 & $\begin{array}{l}\text { User click on surfing in water page } \\
\text { and navigate to surfing page }\end{array}$ & Surfing page is displayed & Surfing page \\
\hline TC_010 & $\begin{array}{l}\text { User click on Shop icon and navigate } \\
\text { to the Bike feature page }\end{array}$ & Bike page is displayed & Bike page \\
\hline TC_011 & $\begin{array}{l}\text { User click on MTB-Hardtail and } \\
\text { navigate to Hardtail mountain } \\
\text { bike page }\end{array}$ & $\begin{array}{l}\text { Hardtail mountain bike page is } \\
\text { displayed }\end{array}$ & Hardtail page \\
\hline TC_012 & $\begin{array}{l}\text { User click on Shop icon and } \\
\text { navigate to Bike \& Frames feature }\end{array}$ & $\begin{array}{l}\text { Bikes \& Frames features page is } \\
\text { displayed }\end{array}$ & $\begin{array}{l}\text { Bikes \& Frames } \\
\text { page }\end{array}$ \\
\hline TC_013 & $\begin{array}{l}\text { User click on service icon and } \\
\text { navigate to Bike workshop page }\end{array}$ & Workshop page is displayed & Workshop page \\
\hline TC_014 & $\begin{array}{l}\text { User click on the Search button and } \\
\text { search for shoes }\end{array}$ & Shoe page is displayed & Shoe page \\
\hline TC_015 & $\begin{array}{l}\text { User click on the Search button and } \\
\text { search for socks }\end{array}$ & Socks page is displayed & Socks page \\
\hline TC_016 & $\begin{array}{l}\text { User click on the Search button and } \\
\text { search for jackets }\end{array}$ & Jackets page is displayed & Jacket page \\
\hline TC_017 & $\begin{array}{l}\text { User click on the Search button and } \\
\text { search for boats }\end{array}$ & Boat page is displayed & Boat page \\
\hline TC_018 & $\begin{array}{l}\text { User click on the Search button and } \\
\text { search for bike }\end{array}$ & Bike page is displayed & Bike page \\
\hline TC_019 & $\begin{array}{l}\text { lick on add to cart for the item user } \\
\text { selected }\end{array}$ & Item has been added to cart & Add to cart \\
\hline TC_020 & Click on proceed to checkout & $\begin{array}{l}\text { My details page should be } \\
\text { displayed }\end{array}$ & Checkout \\
\hline TC_021 & $\begin{array}{l}\text { The user enters the email id and clicks } \\
\text { on the next page }\end{array}$ & $\begin{array}{l}\text { Delivery and payment } \\
\text { details page should be displayed }\end{array}$ & Checkout \\
\hline TC_022 & $\begin{array}{l}\text { User fills the details first name, last } \\
\text { name, phone number, and } \\
\text { clicks on continue to delivery }\end{array}$ & $\begin{array}{l}\text { Delivery options page should be } \\
\text { displayed }\end{array}$ & Checkout \\
\hline TC_023 & $\begin{array}{l}\text { User fills the address details and } \\
\text { clicks on continue to payment }\end{array}$ & $\begin{array}{l}\text { Payment details page should be } \\
\text { displayed }\end{array}$ & Checkout \\
\hline TC_024 & $\begin{array}{l}\text { User enter the credit card number, } \\
\text { expiry date, name on card, CVC and } \\
\text { click on } \\
\text { complete purchase }\end{array}$ & Your credit card number is invalid & Checkout \\
\hline
\end{tabular}

Table 3:Performance Test Cases

\subsection{Test Scripts}

For accurate performance testing results, the test environment should be similar to the production environment. To achieve that, the whole application infrastructure should be thoroughly analyzed. Torpedo7 website which is subjected to the performance testing is already in the production environment since it is a live website. To avoid the external heavy load as much as possible, it is better to conduct the performance test after 10 p.m. as there will be fewer users accessing the Torpedo7 website at that time. Performance testing is conducted using JMeter to check the behavior of the Torpedo7 website on different load conditions. First, the performance test is conducted for 200 users with 3000 seconds ramp-up period for 3000 seconds. 
Computer Science \& Information Technology (CS \& IT)

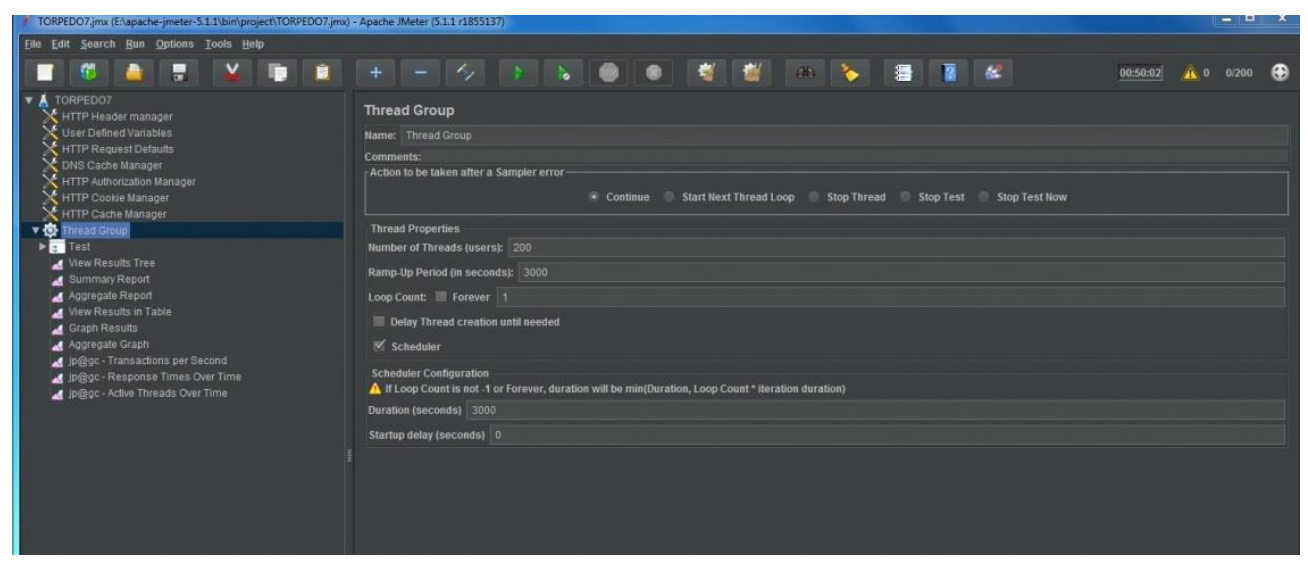

Figure 2: Test Scenario 1

Secondly, users were increased up to 500 and performance testing is conducted with 3000 seconds ramp-up period for 3000 seconds.

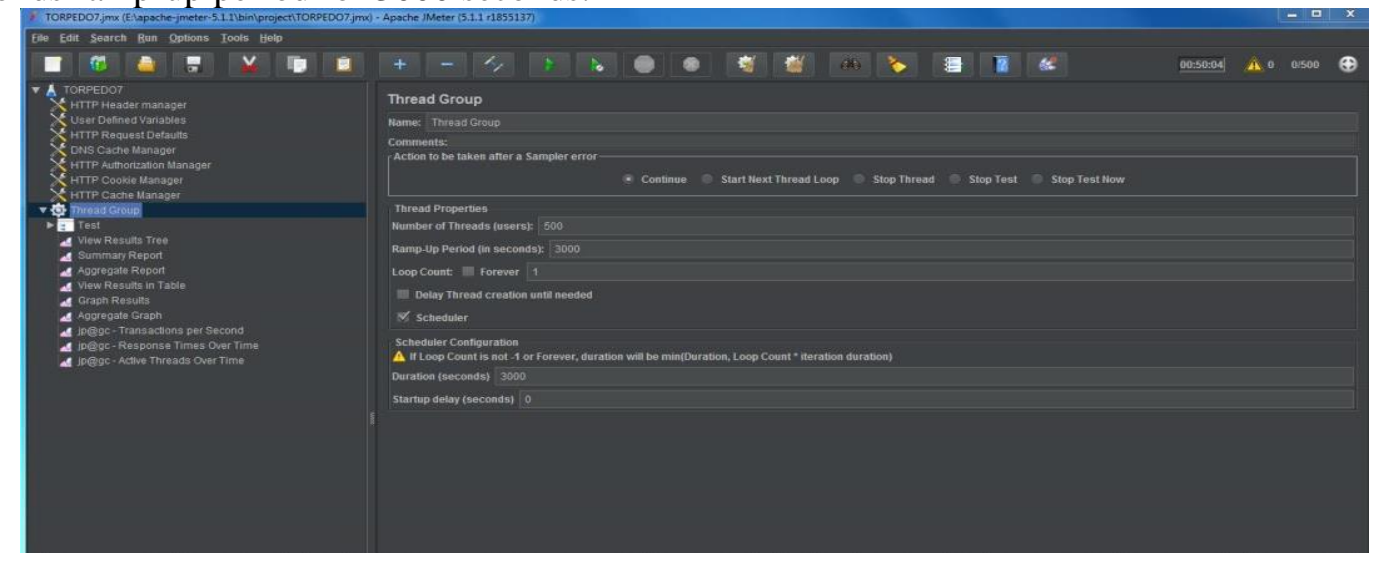

Figure 3: Test Scenario 2

Test Plan named TORPEDO7 was created to test the performance of the www.torpedo7.co.nz website using JMeter. Test scripts were recorded using Blaze Meter in the Chrome browser and exported to JMeter as JMX file.

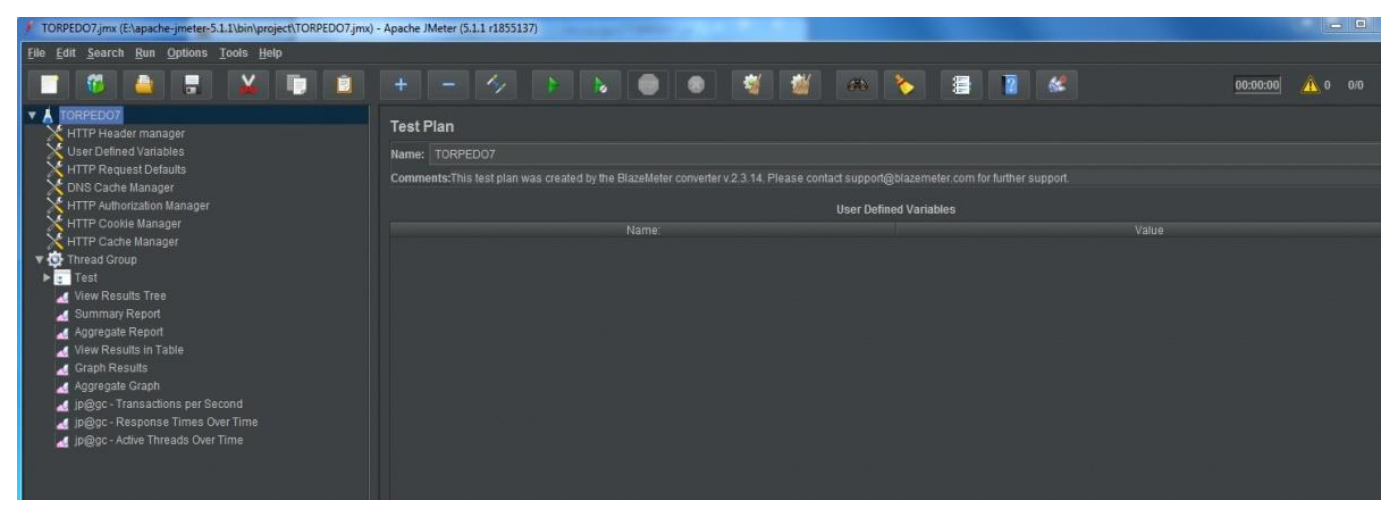

Figure 4: Test Plan

There are few Configuration Elements added to the Test Plan. Some of them are listed below: 
1. HTTP Header Manager is added to the test plan at the Thread Group level which carries header information of requests.

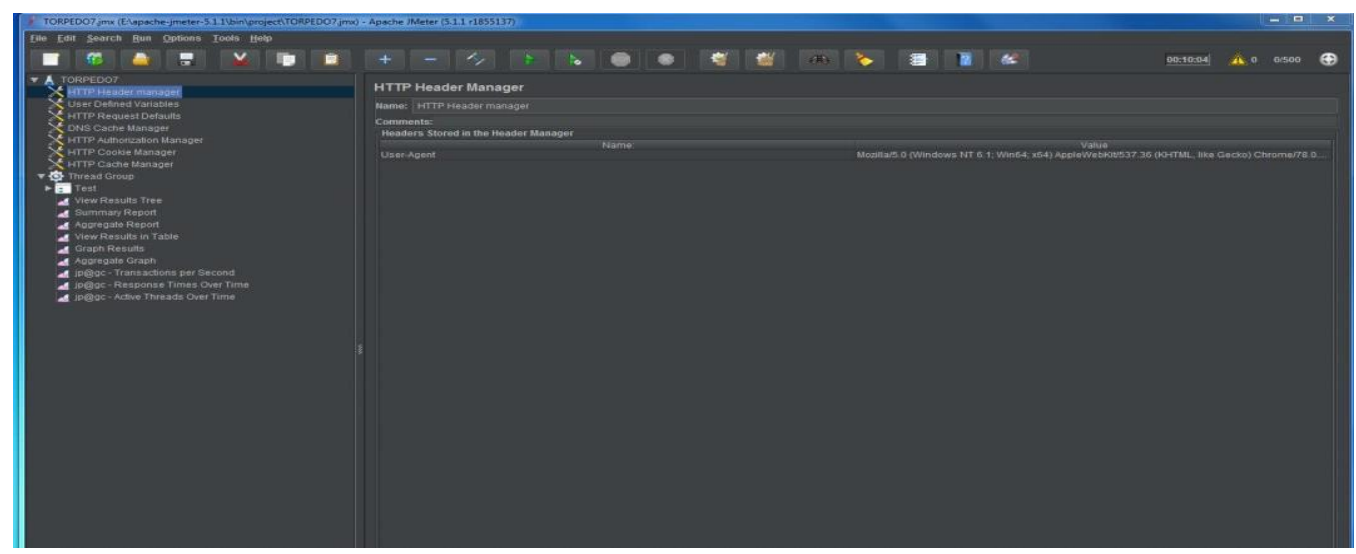

Figure 5: HTTP Header Manager

2. User-Defined Variables have been added to the Thread Group.

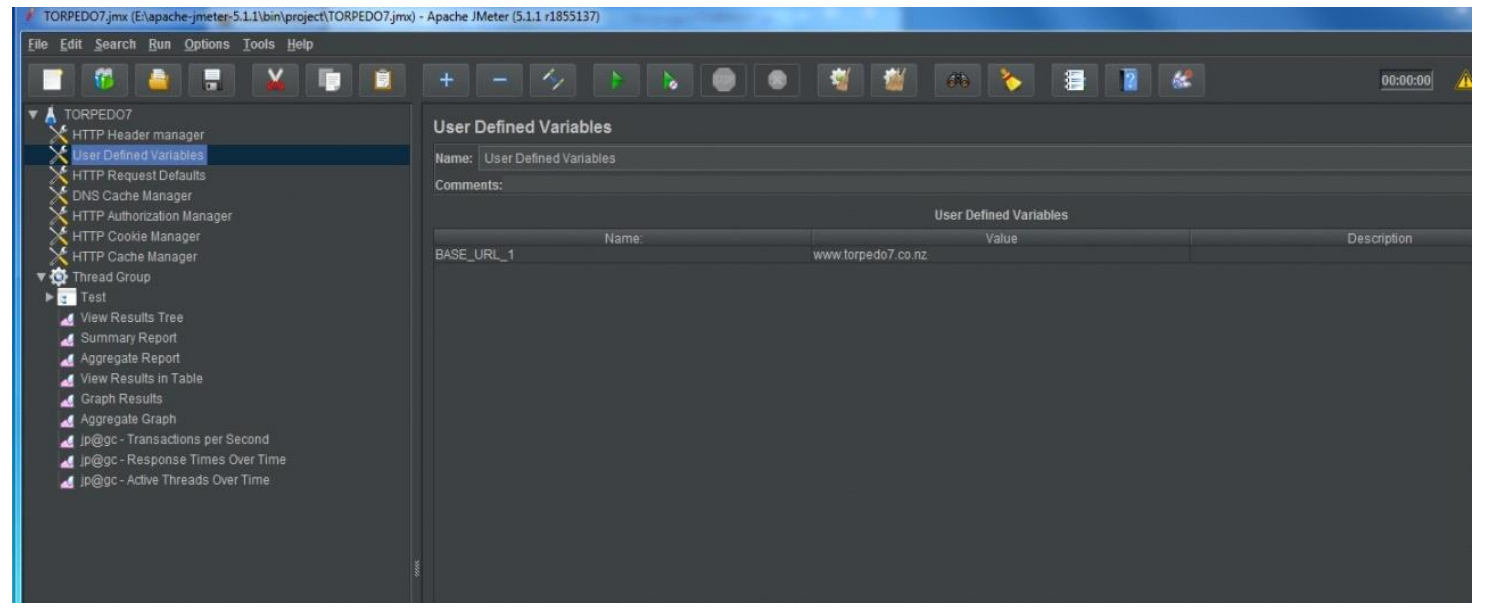

Figure 6: User-Defined Variables

3. HTTP Request Defaults have been added at the Thread Group level. Base URL is given there which is passed to every request.

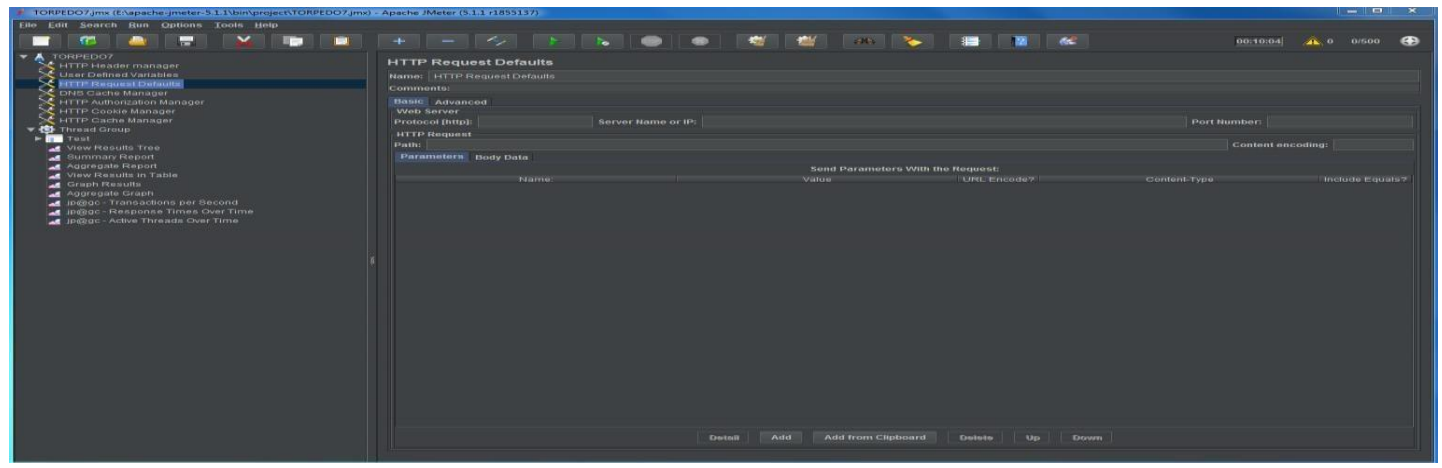

Figure 7: HTTP Request Defaults 
4. DNS Cache Manager is added to the test plan at the Thread Group level. Clear cache each iteration option is selected to clear the DNS cache after each iteration.

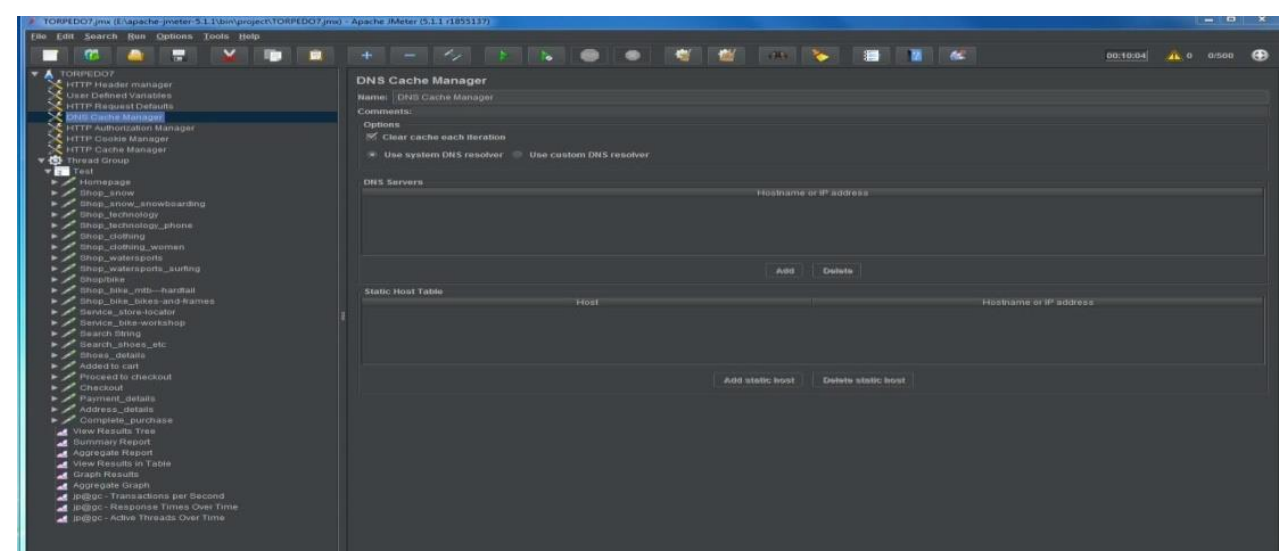

Figure 8: DNS Cache Manager

5. HTTP Cookie Manager is added at the Thread Group level. Clear cookies each iteration option is selected to clear HTTP Cookie data after each iteration.

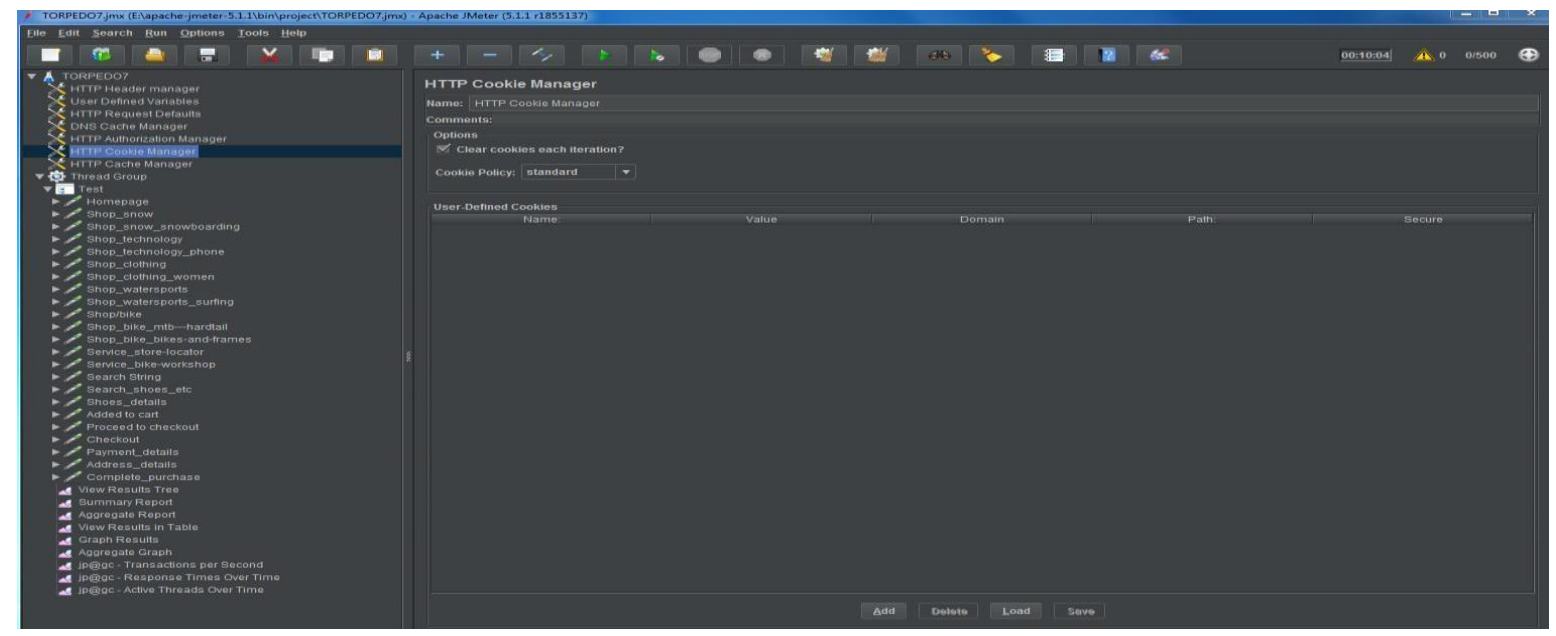

Figure 9: HTTP Cookie Manager

6. HTTP Cache Manager is added to the test plan at the Thread Group level. Clear cache each iteration option is selected to clear HTTP cache after each iteration and a maximum number of elements in the cache is set to 5000 . 


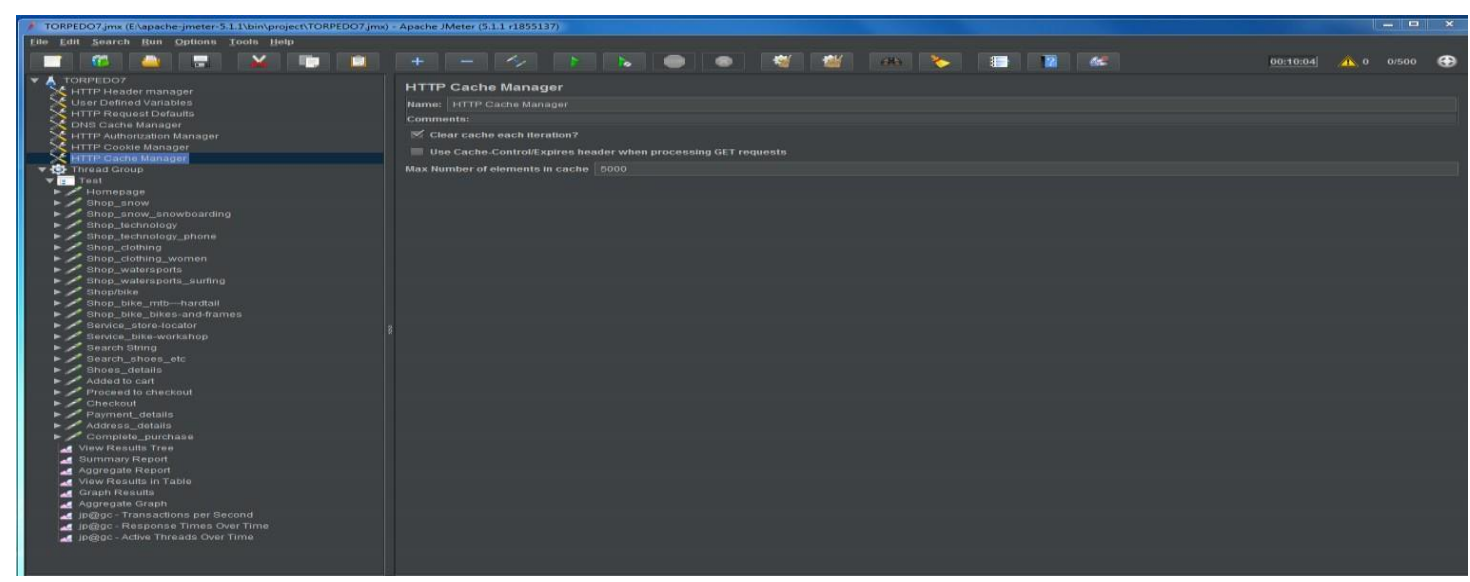

Figure 10: HTTP Cache Manager

Adding Parameters: Added parameters in Search String like shoes, socks, jackets, boats, bike

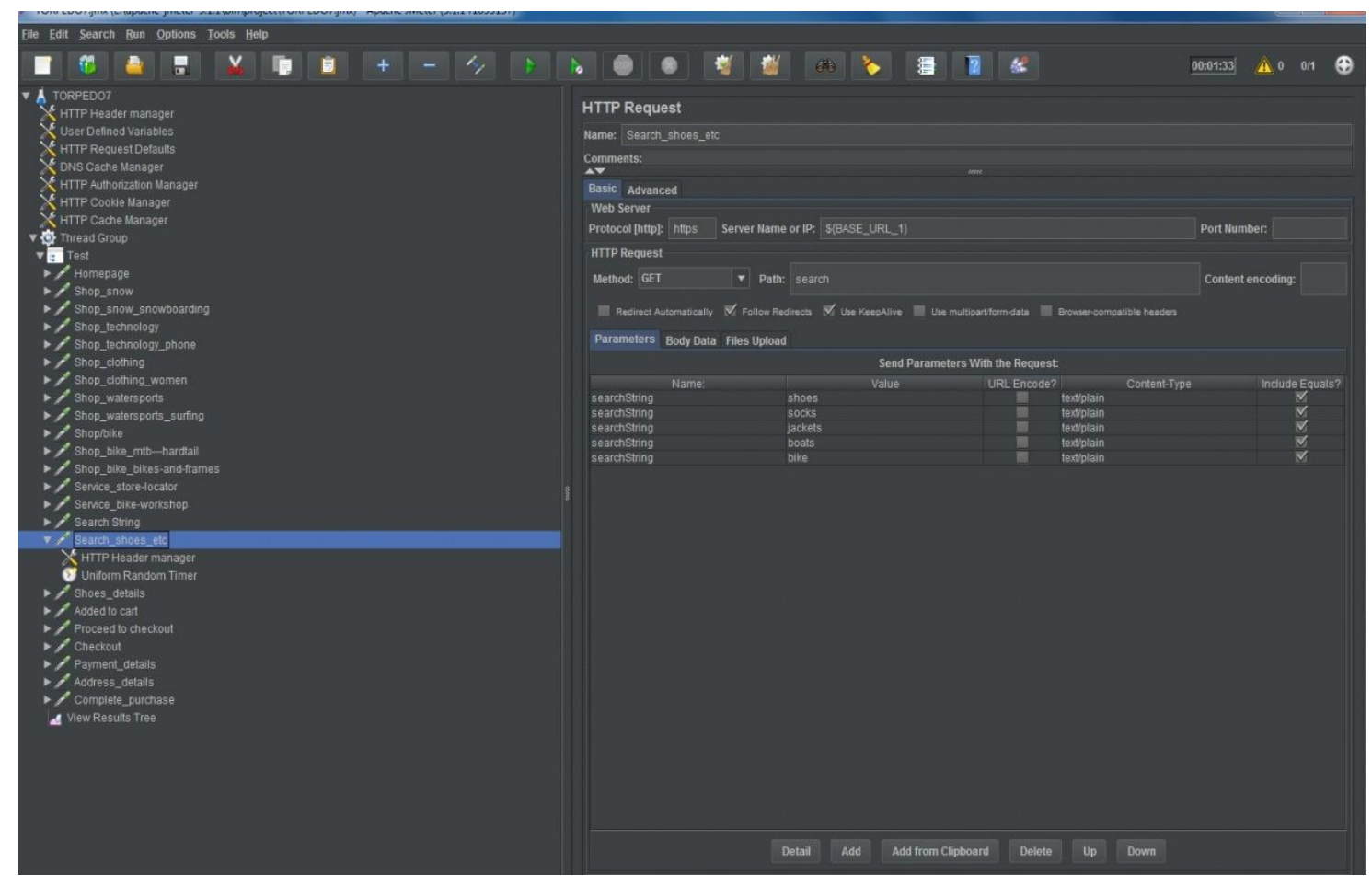

Figure 11: Adding Parameters

Generation of CSV file and HTML report: Using this command prompt generated CSV file for 200 users. 


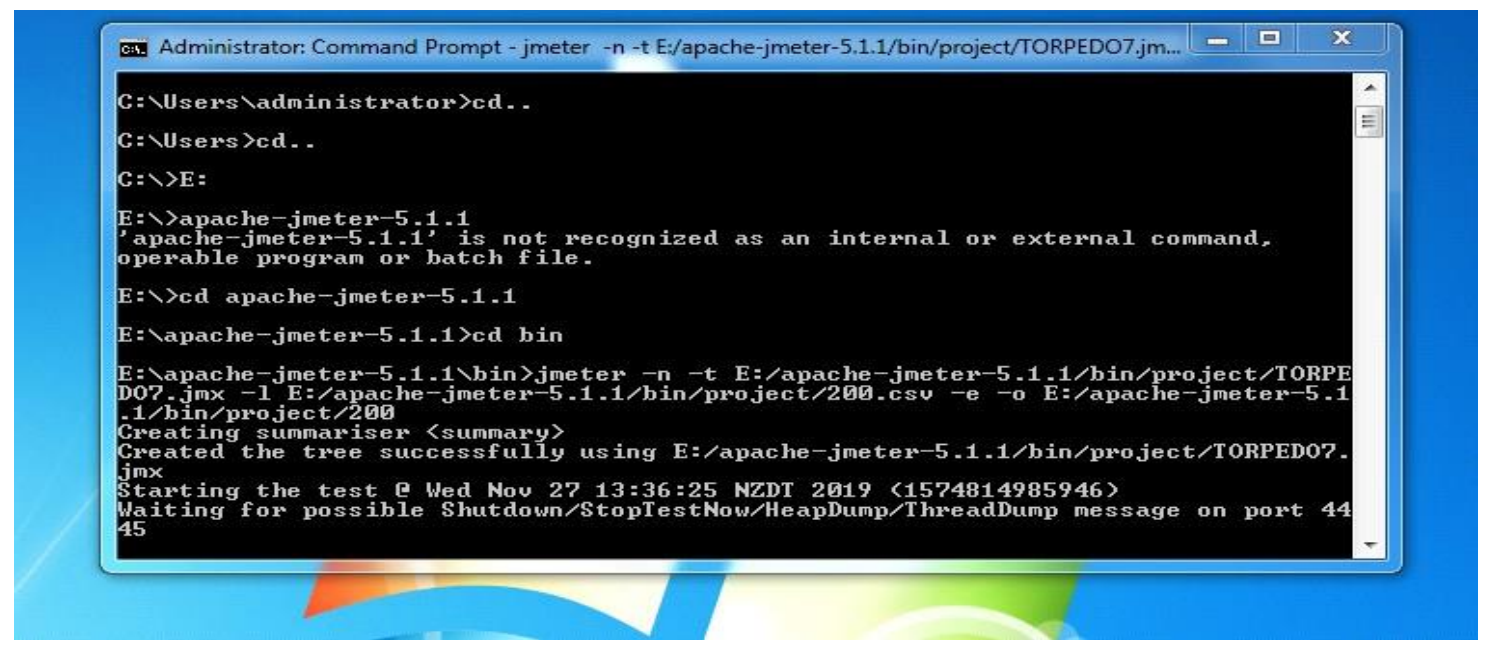

Figure 12: Command Prompt for 200 users

Generation of CSV file and HTML report: Using this command prompt generated CSV file for 500 users.

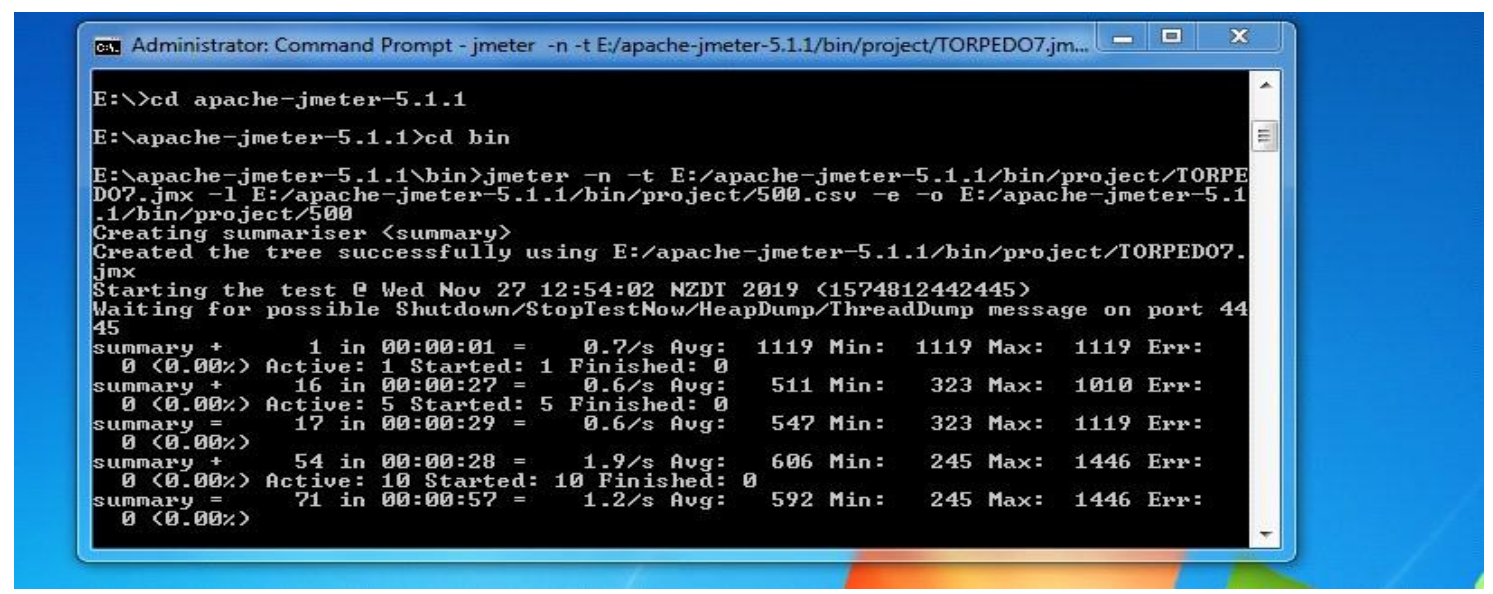

Figure 13: Command Prompt for 500 users

To create CSV file and HTML report in NON-GUI Mode we use the following command:

Jmeter $\quad$-n $\quad$-t $\quad$ E:/apache-jmeter-5.1.1/bin/documents/Homepage.jmx $\quad-1 \quad$ E:/apache-jmeter5.1.1/bin/documents/test2.csv -e -o E:/apache-jmeter-5.1.1/bin/documents/htmlreport

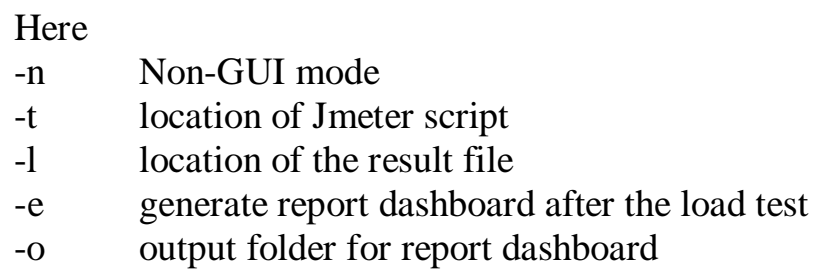




\section{Discussion}

\subsection{Analysis of Web Application Performance}

\subsubsection{Aggregate Report Comparison}

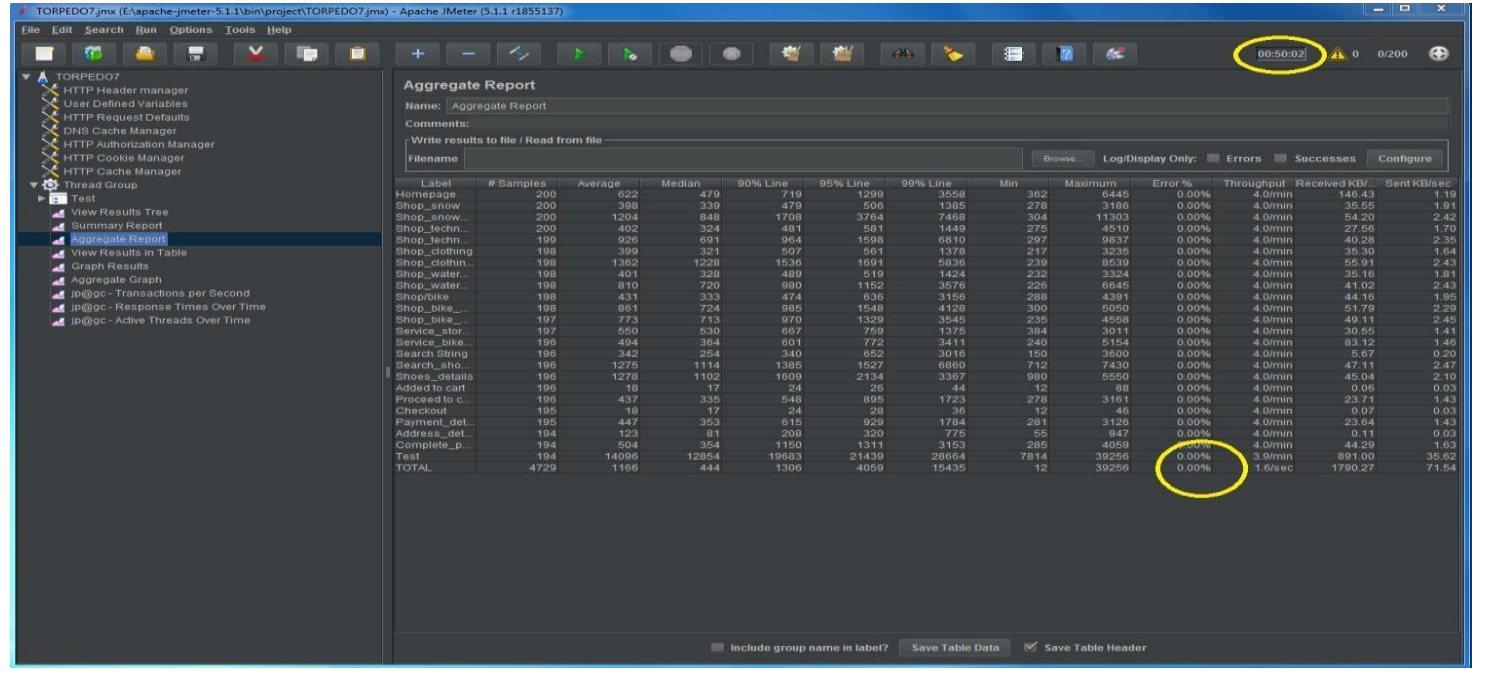

Figure 14: Aggregate Report (200 Threads)

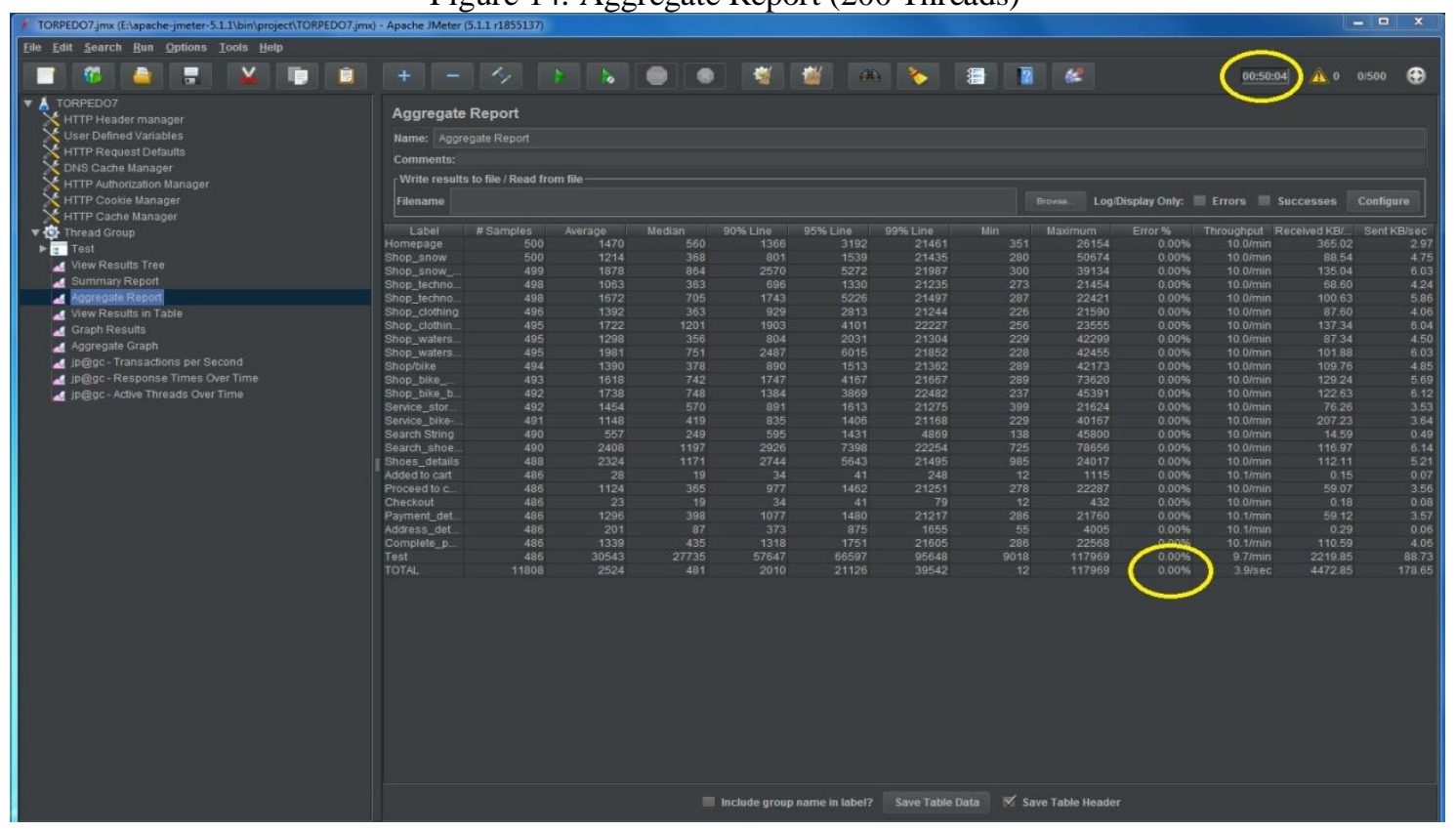

Figure 15: Aggregate Report (500 Threads)

- The aggregate report is the default report in JMeter.

- The aggregate report creates a table row for each differently named request in our test, which is similar to the summary report.

- We should mention the label names correctly to get the best results from the report. 
- For both the scenarios, labels are the same as homepage, shop, service, add to cart and checkout.

- And when comparing samples, average, min, max, sent, received, std dev, throughput, avg bytes all values are different due to network issues.

- $\quad$ Errors for both the scenarios are showing $0 \%$ because all the tests are passed here.

- If anyone of the tests is failed, we get values in errors.

\subsubsection{Aggregate Graph Comparison}

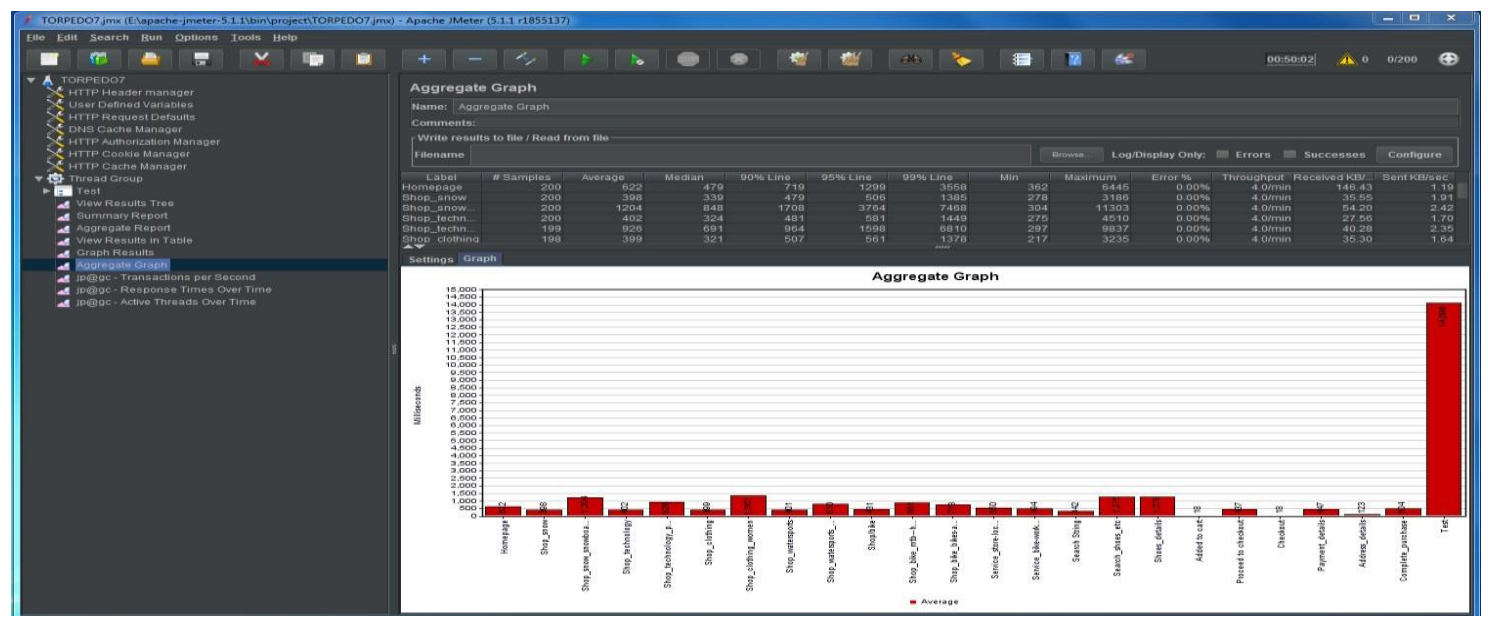

Figure 16: Aggregate Graph (200 Threads)

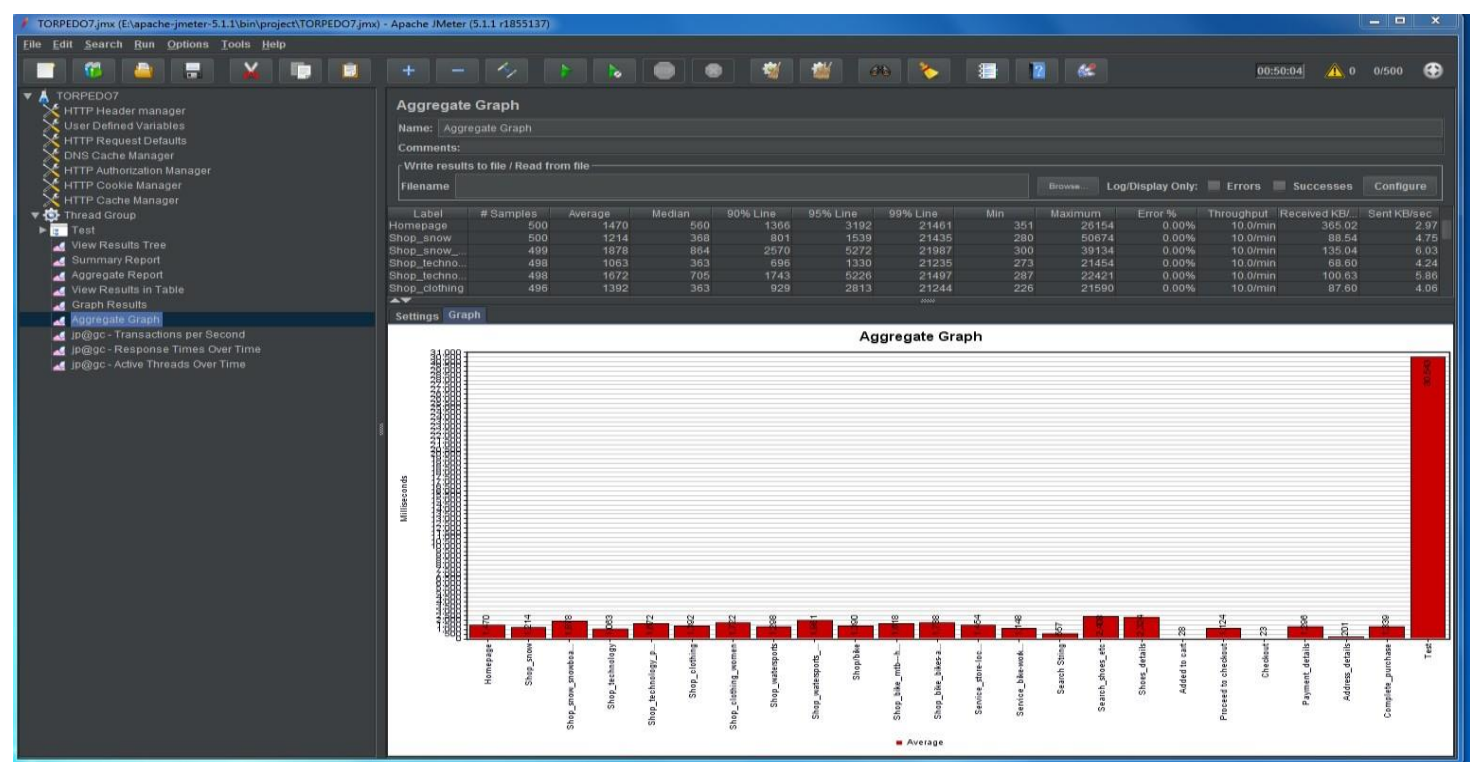

Figure 17: Aggregate Graph (500 Threads)

- The above figures compare the Average Response time and Median Response Time for every single request. 
- According to the above two graphs, there is a huge difference between Average Response Time for 200 threads and for 500 threads for each request.

- There is also a huge difference between Median Response Time for 200 threads and for 500 threads for every single request.

- Finally, there is more deviation between Average Response Time and Median Response Time for each request.

\subsubsection{Transaction per Second Graph comparison}

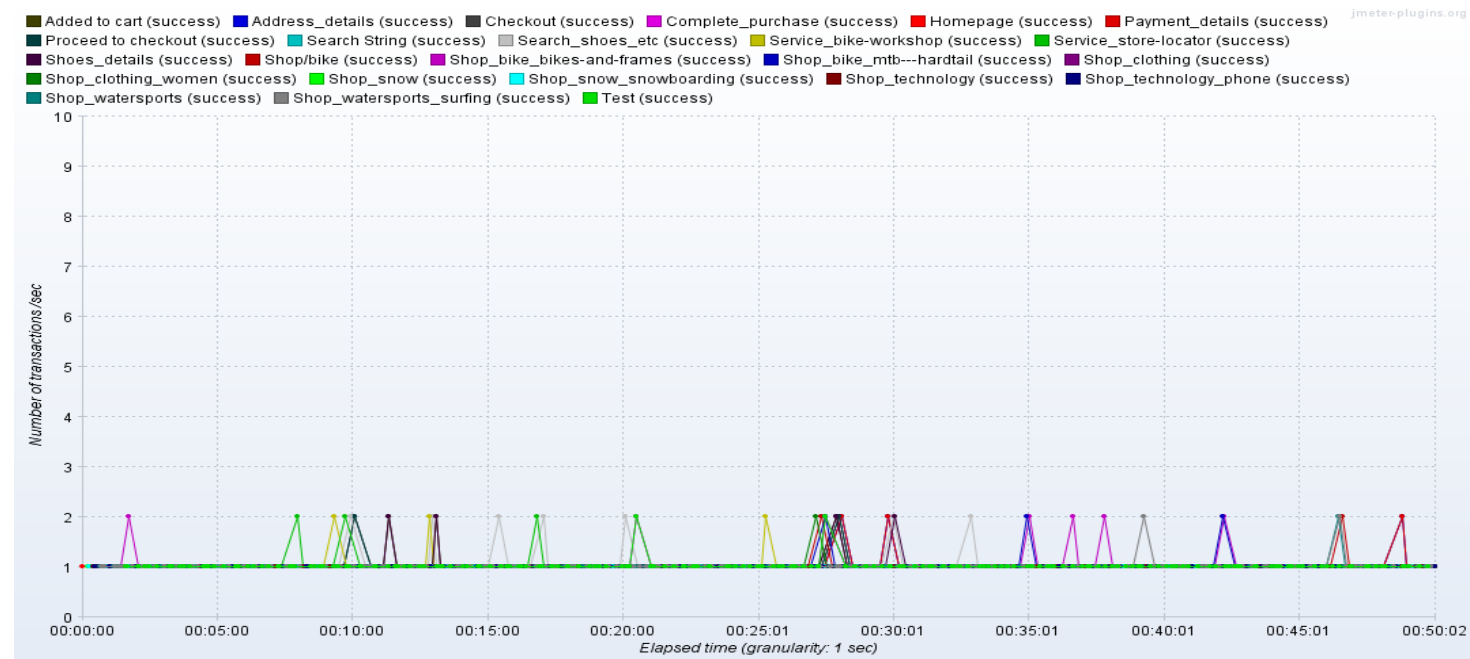

Figure 18: Transaction per Second Graph (200 Threads)

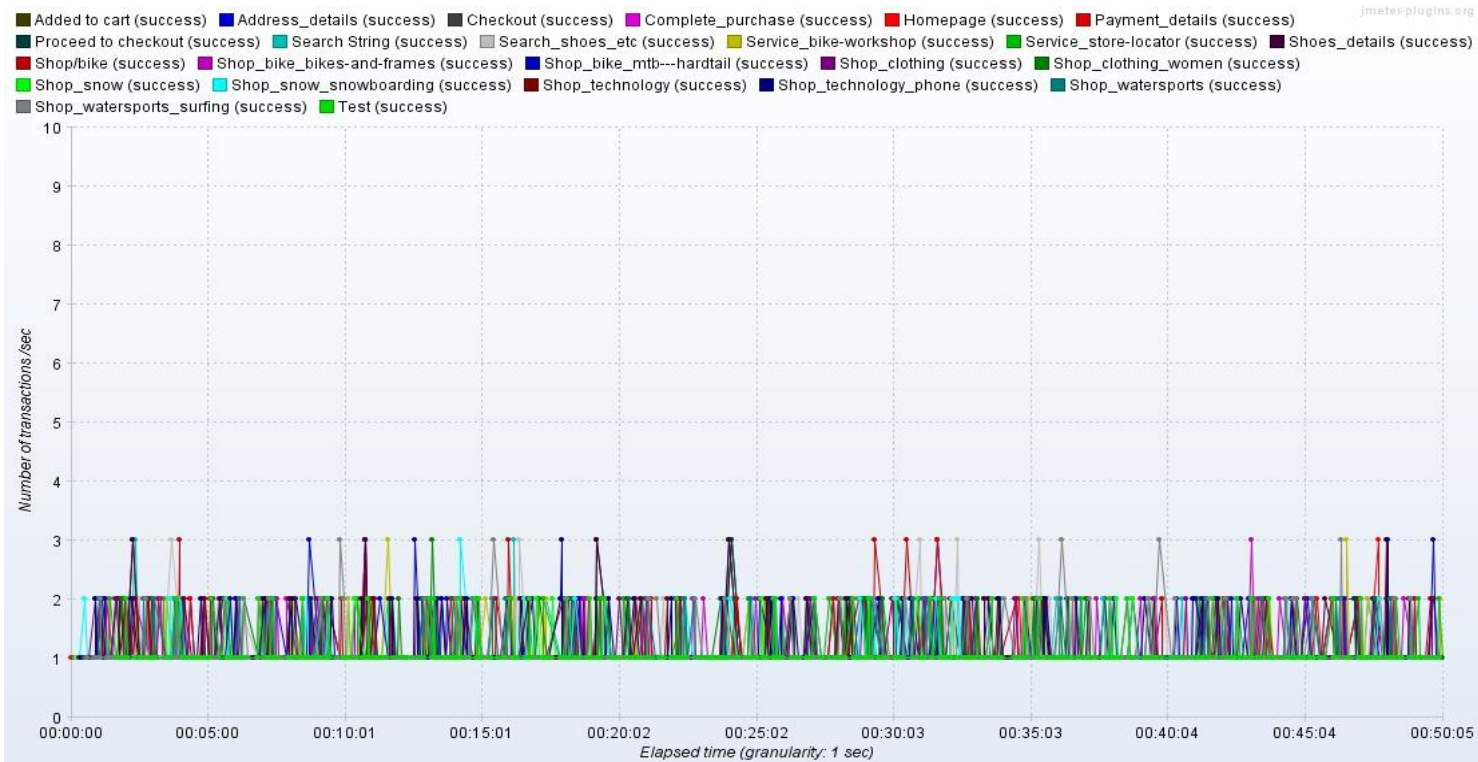

Figure 19: Transactions per Second Graph (500 Threads)

- The above figures 57,58 show the Transactions per Second for 200,500 Threads 
- In figure 57 the transactions per second are 1 or 2 all the time.

- But when the threads increased from 200 to 500 transactions per second also increased mostly and reached to 3 .

\subsubsection{Graph Results comparison}

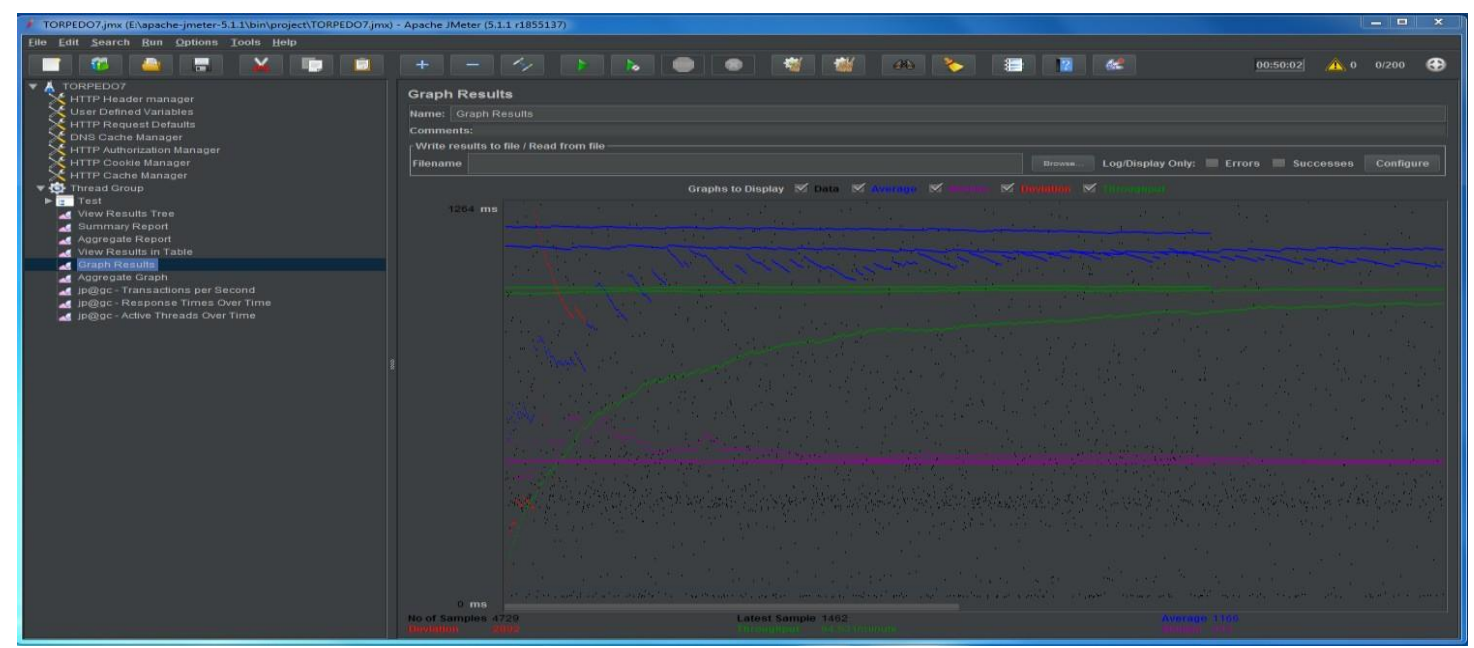

Figure 20: Graph Results (200 Threads)

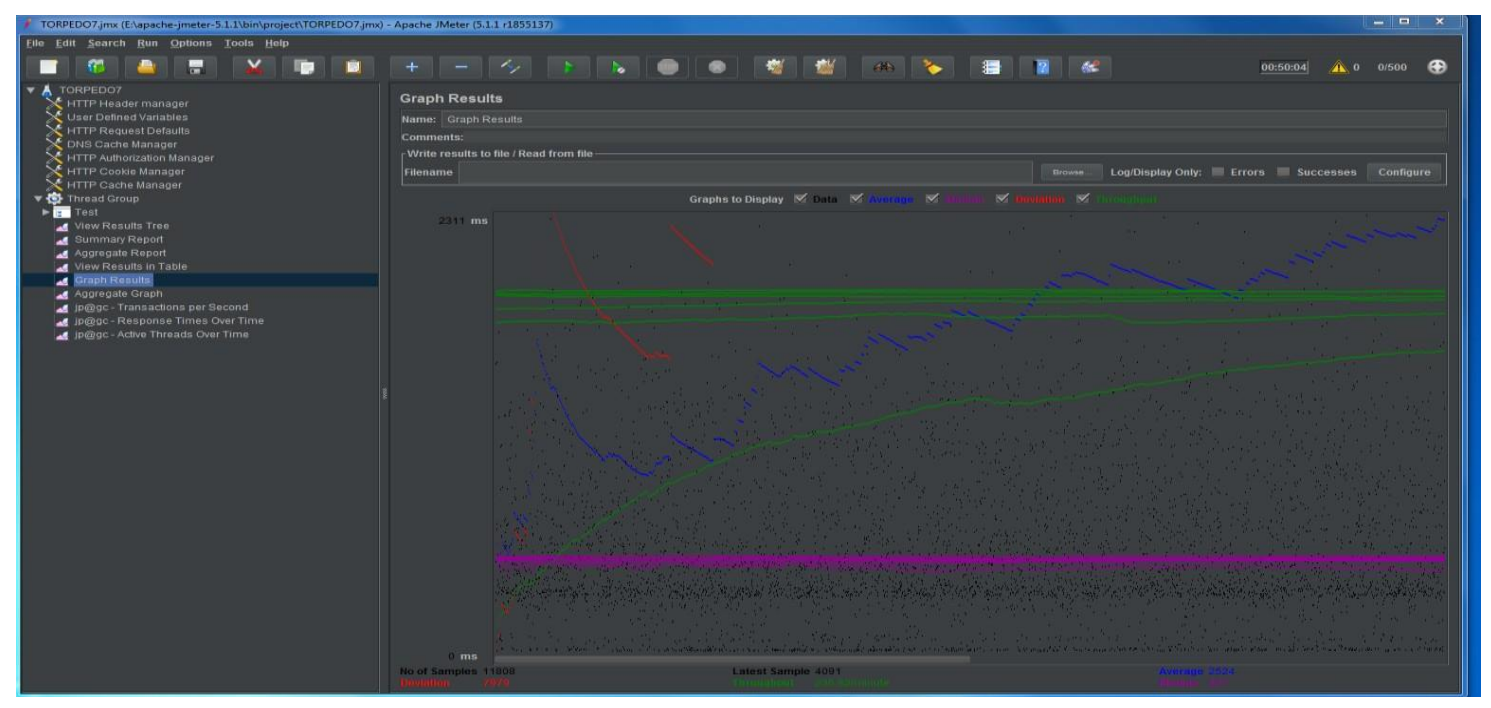

Figure 21: Graph Results Graph (500 Threads)

- This is the most important graph that shows the Median, Average response time, Deviation from the response time and Throughput.

- In figure 60 throughput gradually increased very high nearly two times compared to figure 59 , because the first graph is for 200 threads and the second is for 500 threads. 


\begin{tabular}{|c|c|c|}
\hline & (200 Threads) & (500 Threads) \\
\hline Throughput & 94.531/minute & 235.82/minute \\
\hline
\end{tabular}

- There is some difference between 200 threads and 500 threads in average response time, median and deviation.

\begin{tabular}{|l|l|l|}
\hline & $(200$ Threads $)$ & $(500$ Threads $)$ \\
\hline Average Response Time & 1166 & 2524 \\
\hline Median & 444 & 481 \\
\hline Deviation & 2892 & 7979 \\
\hline
\end{tabular}

In performance testing we start our script with recording, once we finish with recording, then we open our script and run. However, the first step we need to do in performance testing after recording is to identify the main major requests and delete all the redirected ones, otherwise we will end up with the issues frequently.

This research project report was generated with 200 users and 500 users, but when we started our test with 10 and 50 users we did not face any issues. But once we increased the test from 200 users to 500 users at the time of execution, we faced some issues then we performed brainstorming why are we getting issues for 200 users but not for 20,50 users?

In our research we came to know that in performance testing there are some issues, for example the server should be able to handle all token ids because each run creates freshly ids and server can note handle 500 requests. For this we slowly increased the number of threads and we observed firstly for 50 users then for 100 users so on and if errors were encountered after $\mathrm{X}$ numbers of users then it meant that the server was not ready to accept after that thread. We increased the number of users slowly like 20,30,40,50, 100 for 500 so on. Further it required more understanding. So, we increased the ramp-up time and duration and observed for 50 users at the beginning then increased the threads to 100 users then later to 200 and 500.

\section{CONClusion}

Torpedo7 website report covers a brief introduction about Flipmind Company and what they do in New Zealand and Torpedo7 website. Flipmind Company is using an agile methodology for its Torpedo7 website project. Torpedo7 website needs performance testing for Black Friday and Christmas deals. Using the JMeter tool created test scripts and analyzed the results. A load test is done for the Torpedo7 website using JMeter for the Homepage, Shop feature, Service feature, Search functionality, add to cart and checkout with 200, 500 users and hence analyzed the results using summary report, graphs, CSV file, and HTML report.

\section{RECOMMENDATIONS}

Torpedo7 website was tested with 200, 500 threads. With the analysis of test results, the current system is optimal for handling increased traffic on the website. Further, it does not need any upgrades now. The graphs will not remain the same every time because of the load stress or network issue. To get the proper and exact results it recommends executing the test night after $10 \mathrm{pm}$. Especially if working on the performance testing on live websites, it is always recommended to run the load test at night-time to get accurate results. 


\section{REFERENCES}

[1] Patil, S. S., \& Joshi, S. D. (2012). Identification of Performance Improving Factors for Web Application by Performance Testing. Int. J. Emerg. Technol. Adv. Eng., 2(8), 433-436.

[2] Arul, D. P., \& Asokan, M. (2014). Load testing for query based e-commerce web applications with cloud performance Testing Tools. International Journal of Computer Engineering \& Technology (IJCET), 5(10), 01 10.

[3] Chandel, V., Patial, S., \& Guleria, S. (2013). Comparative Study of Testing Tools: Apache JMeter and Load Runner. International Journal of Computing and Corporate Research, 3(3).

[4] Khan, R., \& Amjad, M. (2016). Performance testing (load) of web applications based on test case management. Perspectives in Science, 8, 355-357.

[5] Laanti, M., Salo, O., \& Abrahamsson, P. (2011). Agile methods rapidly replacing traditional methods at Nokia: A survey of opinions on agile transformation. Information and Software Technology, 53(3), 276-290.

[6] Khan, R., \& Amjad, M. (2016). Performance testing (load) of web applications based on test case management. Perspectives in Science, 8, 355-357.

[7] Erinle, B. (2013). Performance testing with JMeter 2.9. Packt Publishing Ltd.

[8] Arul, D. P., \& Asokan, M. (2014). Load testing for query based e-commerce web applications with cloud performance Testing Tools. International Journal of Computer Engineering \& Technology (IJCET), 5(10), 01 10 .

[9] Zhu, K., Fu, J., \& Li, Y. (2010). Research the performance testing and performance improvement strategy in web applications. In 2010 2nd international Conference on Education Technology and Computer (Vol. 2, pp. V2328). IEEE.

[10] Van, P. H. O., Phipps, D. A., \& Lin, S. (2016). U.S. Patent Application No. 14/730,692.

[11] Rasal, Y. M., \& Nagpure, S. (2015). Web application: Performance testing using the reactive based framework. IJRCCT, 4(2), 114-118.

[12] Kao, C. H., Lin, C. C., \& Chen, J. N. (2013). Performance testing framework for rest-based web applications. In 2013 13th International Conference on Quality Software (pp. 349-354). IEEE.

[13] Dhote, M. R., \& Sarate, G. G. (2012). Performance testing complexity analysis on Ajax-based web applications. IEEE Software, 30(6), 70-74.

[14] Kiran, S., Mohapatra, A., \& Swamy, R. (2015). Experiences in performance testing of web applications with Unified Authentication platform using Jmeter. In 2015 international symposium on technology management and emerging technologies (ISTMET) (pp. 74-78). IEEE

[15] Hussain, S., Wang, Z., Toure, I. K., \& Diop, A. (2013). Web service testing tools: A comparative study. arXiv preprint arXiv:1306.4063.

[16] Patil, S. S., \& Joshi, S. D. (2012). Identification of Performance Improving Factors for Web Application by Performance Testing. Int. J. Emerg. Technol. Adv. Eng., 2(8), 433-436.

[17] Sharma, M., Vaishnavi, S. I., Sugandhi, S., \& Abhinandhan, S. (2016). A comparative study of load testing tools. International Journal of Innovative Research in Computer and Communication Engineering, 4(2), 1906-1912.

[18] Jha, N., \& Popli, R. (2017). Comparative analysis of web applications using JMeter. International Journal of Advanced Research in Computer Science, 8(3).

[19] Arslan, M., Qamar, U., Hassan, S., \& Ayub, S. (2015). Automatic performance analysis of cloudbased load testing of web-application \& its comparison with traditional load testing. In 2015 6th 
IEEE International Conference on Software Engineering and Service Science (ICSESS) (pp. 140144). IEEE.

[20] Bhardwaj, S., \& Sharma, A. K. (2015). Performance Testing Tools: A Comparative Analysis. International Journal of Engineering Technology, Management and Applied Sciences, 3(4).

\section{Authors}

\section{First Author}

I am Sushma. I have completed my Bachelor's in Computers Science from JNTU University India. I have recently completed my graduate diploma in Software Testing from AGI Education Limited New Zealand. I am passionate about testing and love to deliver quality products to customers.

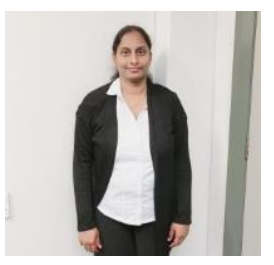

\section{Second Author}

Dr. Shahid Ali is a senior lecturer and IT program leader at AGI Education Limited, Auckland, New Zealand. He has published number of research papers on ensemble learning. His expertise and research interests include ensemble learning, machine learning, data mining and knowledge discovery.

(C) 2020 By AIRCC Publishing Corporation. This article is published under the Creative Commons Attribution (CC BY) license. 